\title{
Non-IgE-Dependent Hypersensitivity to Rocuronium Reversed by Sugammadex: Report of Three Cases and Hypothesis on the Underlying Mechanism
}

\author{
David Spoerl ${ }^{\mathrm{a}}$ Stéphanie D'Incau ${ }^{\mathrm{b}}$ Pascale Roux-Lombard ${ }^{\mathrm{C}}$ Thomas Harr $^{\mathrm{a}}$ \\ Christoph Czarnetzkid \\ ${ }^{a}$ Division of Clinical Immunology and Allergy, Department of Medical Specialties, ${ }^{b}$ Department of Internal and \\ General Medicine, 'Division of Laboratory Medicine, Department of Genetics and Laboratory Medicine, and \\ ${ }^{\mathrm{d}}$ Division of Anesthesiology, Geneva University Hospital, Geneva, Switzerland
}

\section{Established Facts}

- Rocuronium has been shown to activate the MRGPRX2 receptor on mast cells, inducing a non-IgEmediated histamine release, which explains its potential for causing pseudoallergic reactions.

- Sugammadex has been designed to encapsulate rocuronium and specifically antagonize its pharmaceutical effects.

- There are several case reports describing the reversal of rocuronium-induced anaphylaxis by the injection of sugammadex; however, the exact pathophysiological mechanism is still unknown.

\section{Novel Insights}

- Sugammadex was successfully used in 3 patients to rapidly reverse ongoing pseudoallergic reactions.

- Sugammadex abolished the rocuronium-induced irritative skin test reaction in the 3 patients and in 3 healthy individuals, suggesting that this effect might be mediated by the inhibition of rocuroniuminduced MRGPRX2 activation.

\section{Key Words}

Anaphylaxis · Anaphylactoid reaction · Rocuronium .

Sugammadex $\cdot$ Receptor

\section{Abstract \\ We present 3 cases of pseudoallergic (anaphylactoid) reac- tions to perioperatively administered rocuronium, which rapidly resolved after sugammadex injection. Allergological workup showed no evidence for immediate-type hypersen- sitivity to the drugs used for anesthesia, including rocuroni-}

um. However, rocuronium induced an irritative reaction in skin tests in all 3 patients and in 3 healthy individuals. This reaction was specifically suppressed by adding sugammadex at a 1:1 molecular proportion to rocuronium before the skin tests. This observation suggests that the patients suffered from a pseudoallergic reaction, and indicates that sugammadex might act via the inhibition of non-IgE mediated MRGPRX2 (Mas-related G-protein-coupled receptor member X2)triggered mast cell degranulation induced by rocuronium.

(c) 2016 S. Karger AG, Basel

T.H. and C.C. contributed equally to this work.

\section{KARGER}

E-Mail karger@karger.com

www.karger.com/iaa (c) 2016 S. Karger AG Basel

$1018-2438 / 16 / 1694-0256 \$ 39.50 / 0$
Correspondence to: Dr. med. David Spoerl

Division of Clinical Immunology and Allergy, Department of Medical Specialties, University Hospital and Faculty of Medicine, University of Geneva rue Gabrielle-Perret-Gentil 4, CH-1211 Geneva 14 (Switzerland)

E-Mail david.spoerl@hcuge.ch 


\section{Introduction}

Approximately $60 \%$ of perioperative hypersensitivity reactions are IgE-mediated anaphylactic reactions, whereas $40 \%$ are pseudoallergic (anaphylactoid) reactions. Neuromuscular blocking agents (NMBA) have been reported to account for the majority of IgE-mediated reactions occurring during general anesthesia $[1,2]$.

Quaternary and tertiary ammonium (QA) ions are thought to be the main allergenic epitopes in NMBAs. Other drugs, such as opiates, and environmental chemicals also contain QA [2-4]. This shared epitope might in part explain the cross-sensitization between different NMBAs, as seen in most patients allergic to NMBAs, and the fact that a history of previous exposure to NMBAs is only found in fewer than $50 \%$ of patients adversely reacting to NMBAs during anesthesia $[5,6]$.

Rocuronium bromide is a nondepolarizing NMBA. Controversies exist as to the best approach to evaluate rocuronium hypersensitivity reactions. Skin tests in healthy individuals have shown a nonirritating concentration at approximately $10^{-4}$ and $10^{-3} \mathrm{M}$ [7]. Fifty percent of healthy individuals show a positive prick test reaction (irritative) with the undiluted drug [8] and current guidelines propose intradermal tests (IDTs) at a dilution of $1: 200$, i.e. $0.05 \mathrm{mg} / \mathrm{ml}$, corresponding to approximately $10^{-4} \mathrm{M}$ [9]. ImmunoCAP assays for the determination of specific IgE to rocuronium have been used in this setting (specificity 93\%, sensitivity 68\%) [10]. The testing of specific IgE to QA is otherwise more widely available.

Sugammadex has been specifically designed to antagonize rocuronium-induced neuromuscular blockade [11-13].Itschemicalstructureisamodified $\gamma$-cyclodextrin with 8 sugar molecules forming a rigid ring with a central lipophilic cavity designed to incorporate the rocuronium molecule. Sugammadex binds at a 1:1 ratio to rocuronium with an extremely high binding affinity $\left(\mathrm{K}_{\mathrm{a}}=1.8 \times\right.$ $10^{7} \mathrm{M}^{-1}$ ) [5]. Once enveloped with sugammadex, rocuronium is unable to bind to the acetylcholine receptor at the neuromuscular junction. Whether sugammadex is useful for antagonizing IgE-mediated or pseudoallergic reactions due to rocuronium remains a matter of debate [14].

In the following, we report 3 cases of presumed pseudoallergic reactions to rocuronium with a rapid response to sugammadex. In addition, we also propose a hypothesis about the underlying pathological mechanism of this response.

Pseudoallergic Reaction to Rocuronium Reversed by Sugammadex

\section{Case Reports}

Case 1

A 36-year-old atopic female underwent abdominal surgery during which fentanyl, lidocaine, propofol, suxamethonium and ceftriaxone followed by repeated injections of rocuronium were given. At the end of the procedure she presented a generalized urticarial rash associated with bronchoconstriction and hypoxemia. She was treated with antihistamines, methylprednisolone and nebulized adrenaline, but her condition improved rapidly only after treatment with $400 \mathrm{mg}$ i.v. of sugammadex. Tryptase was not measured during the reaction.

Skin tests for penicillin (benzylpenicilloyl octa-L-lysine, benzylpenilloate minor determinant), amoxicillin, ceftriaxone, lidocaine, procaine, fentanyl, suxamethonium, propofol, latex and chlorhexidine were negative. IDT for rocuronium at a concentration of $10 \mathrm{mg} / \mathrm{ml}$ resulted in an erythema without papule formation at the $10^{-3}$ and $10^{-2}$ dilutions, and was clearly positive at the $10^{-1}$ dilution, which is known to be irritative. The mixture of sugammadex and rocuronium (1:1 molecular) was negative in all the tested dilutions (mild erythema at the $10^{-1}$ dilution; fig. 1a). Specific IgEs for penicillin $\mathrm{G}$ and $\mathrm{V}$, ampicillin, amoxicillin, chlorhexidine, QA, rocuronium, suxamethonium, ethylene oxide and latex were negative. A basophil activation test (BAT) with and without the addition of IL-3, measuring CD63 and CD203c expression, was negative for atracurium (concentration 1,000, 100 and $10 \mathrm{ng} / \mathrm{ml}$; highest stimulation index 1.8), chlorhexidine (concentration 100, 10 and $1 \mathrm{ng} / \mathrm{ml}$; highest stimulation index 2.0), rocuronium (concentration 1,000, 100 and $10 \mathrm{ng} / \mathrm{ml}$; highest stimulation index 1.5) and the mixture of rocuronium and sugammadex (concentration 1,000, 100 and $10 \mathrm{ng} / \mathrm{ml}$; highest stimulation index 0.9 ). The basal tryptase was within the normal range 6 months later.

Case 2

A 48-year-old female was scheduled for surgical resection of an unexplained left parietal cerebral mass. A few minutes after the induction with propofol and fentanyl, and injection of $40 \mathrm{mg}$ of rocuronium, she developed tachycardia and a generalized urticarial rash, followed by profound hypotension (mean arterial pressure between 40 and $50 \mathrm{~mm} \mathrm{Hg}$ ) and metabolic acidosis without hypoxemia. An anaphylactic shock was suspected and hydrocortisone and clemastine were administered once. Despite repeated epinephrine injections and intravenous fluids the patient remained hypotensive and the surgical procedure was cancelled. Fifty-three minutes after the induction, $200 \mathrm{mg}$ of sugammadex were injected, resulting in rapid hemodynamic normalization, disappearance of the urticarial rash and extubation 15 min later. A serological analysis during the anaphylactic reaction showed an elevated tryptase level of $36 \mu \mathrm{g} / \mathrm{l}$ (normal value $<11.1 \mu \mathrm{g} / \mathrm{l}$ ).

Prick tests and IDTs were negative to all substances used during the procedure as well as to latex, ethylene oxide and chlorhexidine. Prick tests were positive to $10 \mathrm{mg} / \mathrm{ml}$ of pure rocuronium and negative for the 1:1 mixture of rocuronium and sugammadex. The IDT to rocuronium was positive at $10^{-2}$ and $10^{-1}$ dilution, which is presumably an irritative dose. An IDT using the 1:1 mixture of rocuronium and sugammadex was negative at dilutions of $10^{-2}$ and $10^{-1}$ (fig. 1b). Specific IgEs were negative for rocuronium, chlorhexidine, suxamethonium, QA, ethylene oxide and latex. BAT was negative for rocuronium, rocuronium and sugammadex mixture, and atracurium (with the same concentrations as in case 1; the 

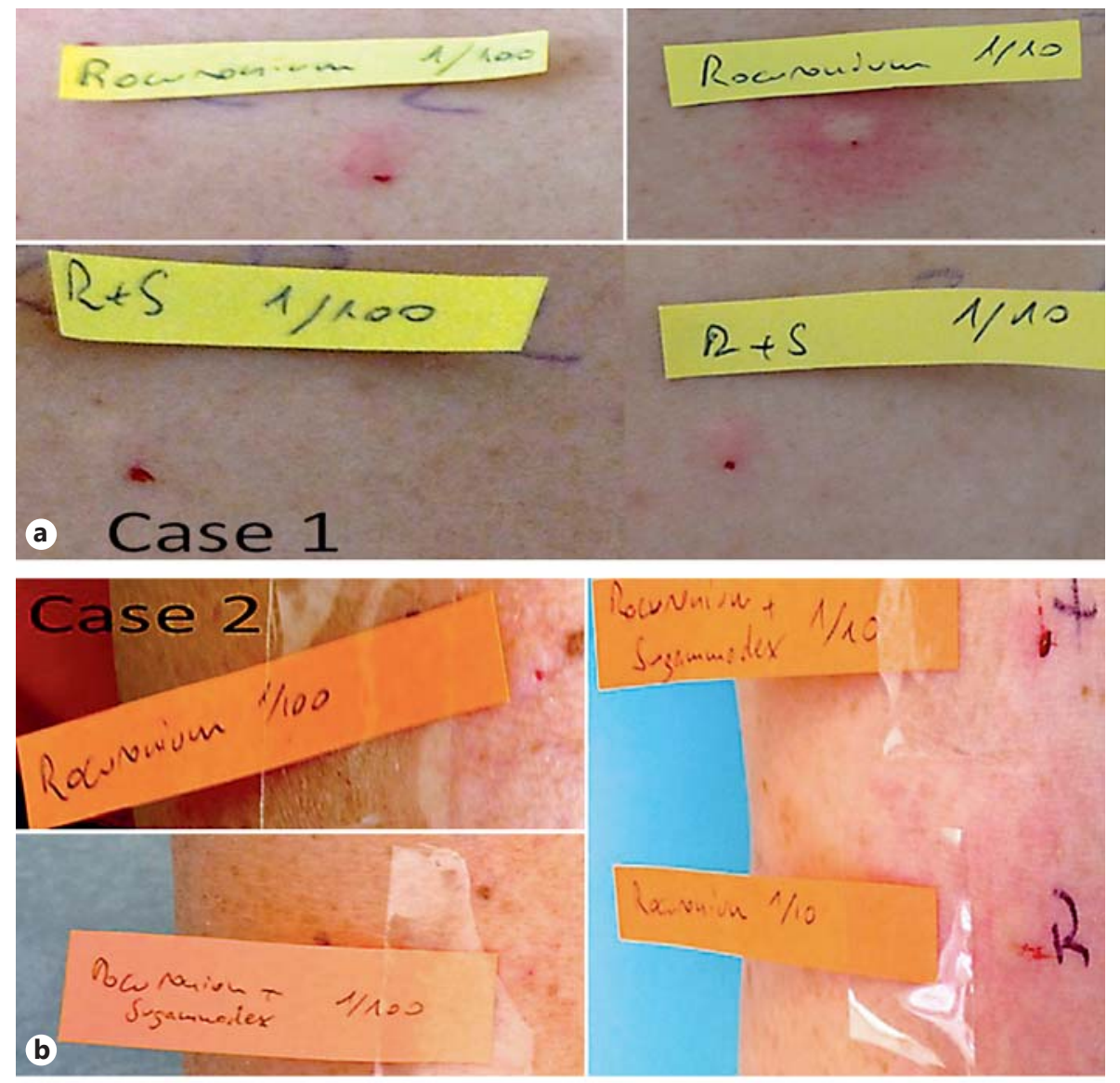

Fig. 1. a-c IDT with rocuronium and rocuronium mixed with sugammadex (1:1 molecular) in 3 cases of probable pseudoallergic reaction following perioperative rocuronium injection. All IDTs were considered either irritative or negative, but when sugammadex was mixed before the IDT, the reaction was attenuated.

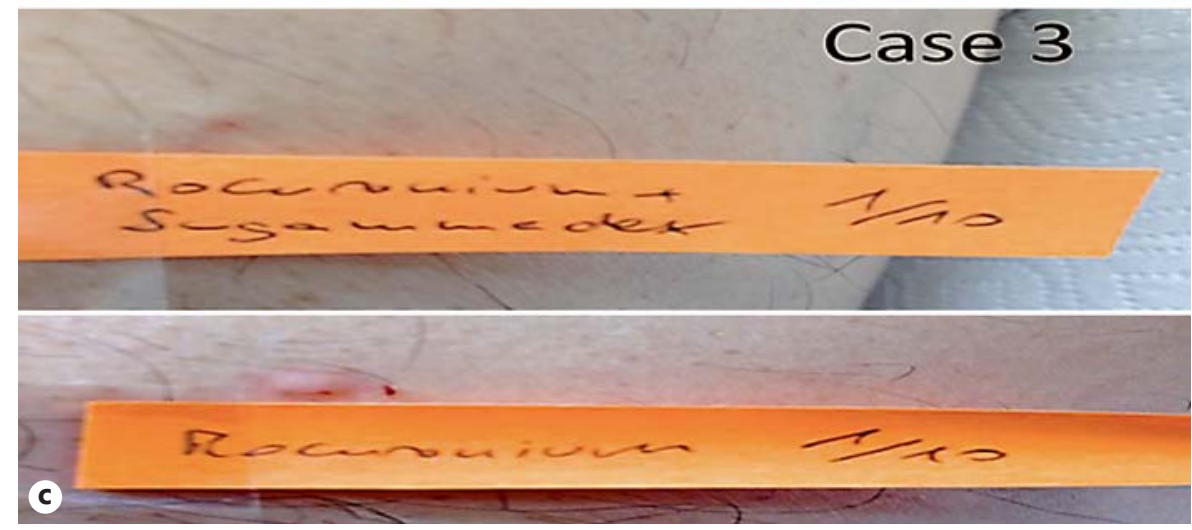

highest stimulation index for rocuronium was 1.9, and for rocuronium and sugammadex mixture was 0.9 ). Basal tryptase was within the normal range.

\section{Case 3}

A 69-year-old male underwent craniotomy for a suspected glioblastoma multiforme. A few minutes after the induction with propofol and sufentanil, and injection of $50 \mathrm{mg}$ of rocuronium and $40 \mathrm{mg}$ of ketamine, he developed severe hypotension (mean arterial pressure between 40 and $50 \mathrm{~mm} \mathrm{Hg}$ ), requiring intravenous fluids and epinephrine (total dose $1.5 \mathrm{mg}$ ). Sixty minutes after the first dose of rocuronium, a second dose of $20 \mathrm{mg}$ was injected to facilitate transesophageal echocardiography, which did not show signs of cardiogenic shock. Forty minutes after the second dose of rocuronium, $400 \mathrm{mg}$ of sugammadex were injected. The blood pressure stabilized rapidly and the patient was extubated after a second dose of $200 \mathrm{mg}$ of sugammadex, injected 20 min later. The patient did not receive corticosteroids or antihistaminic drugs before extubation. Tryptase was within the normal range during the reaction and $2 \mathrm{~h}$ later. The surgery was subsequently postponed. Because of the necessity to rapidly perform the surgical procedure, the skin tests were performed only 3 days after the reaction when 
still under corticosteroid treatment, possibly compromising their validity.

Skin tests for all the substances used during the procedure were negative. However, an IDT for rocuronium was weakly positive at a presumably irritative $10^{-1}$ dilution, and negative for the $1: 1$ rocuronium and sugammadex mixture at the same dilution (fig. 1c). No specific IgEs were found against rocuronium, chlorhexidine, suxamethonium, QA and latex. BAT was inconclusive due to a low basophil count $(<0.01 \%$ of leucocytes). During the following surgical procedure, ketamine, etomidate and isoflurane were used for anesthesia and sufentanil for analgesia. NMBAs were completely avoided.

\section{Discussion}

NMBAs are well known to potentially cause anaphylactic (i.e. IgE-mediated) reactions during anesthesia. However, many reactions to NMBAs occur during the first exposure, suggesting a non-IgE-mediated pathomechanism. Under most circumstances, it is impossible to clinically distinguish an IgE-mediated allergic reaction from a pseudoallergic reaction. NMBAs have direct vasodilating effects on blood vessels. They are able to induce histamine and tryptase release from mast cells within the skin via different mechanisms that might vary depending on the compounds studied [7].

We report 3 cases of probable pseudoallergic reactions to rocuronium, which rapidly resolved after the administration of sugammadex. Tryptase was not measured in the first patient, in the second tryptase was increased during the reaction, and in the third case tryptase was within normal values, possibly due to the low sensitivity of this test [15-17]. Two patients received standard treatment for anaphylaxis, including corticosteroids, antihistaminic drugs and adrenaline, without an apparent response. One patient received only epinephrine. The rapid clinical improvement within minutes after sugammadex in the $3 \mathrm{pa}-$ tients can thus not be explained by the standard treatment for anaphylaxis.

Rocuronium hypersensitivity could not be demonstrated in the 3 patients, neither in vivo by skin tests, nor in vitro by IgE to QA, IgE to rocuronium or BAT. In case 2 , the prick test was positive with pure rocuronium and the IDT was positive at a dilution of $10^{-2}$. In the other 2 patients skin tests with rocuronium were only positive at a dilution of $10^{-1}$. These results were probably due to an irritative reaction. Sugammadex mixed at a 1:1 ratio with rocuronium was able to neutralize the irritative effect of rocuronium in all the performed skin tests. Hypersensitivity to other drugs used during surgery in all 3 patients could not be identified by skin and specific IgE testing as well as BAT.

Pseudoallergic Reaction to Rocuronium

Reversed by Sugammadex
Recently, a mast cell-specific receptor, the human MRGPRX2 (Mas-related G-protein-coupled receptor member X2) has been reported to be involved in pseudoallergic reactions seen in patients after treatment with peptidergic drugs, including rocuronium [18]. It is possible that the high rate of anaphylactic reactions reported in NMBA-naïve patients, as well as the high percentage of cross-reactivity reported in NMBA-allergic patients (mostly based on skin test results), might in fact be due to the effects of NMBA on the MRGPRX2 receptor and, therefore, be pseudoallergic and not anaphylactic. This mechanism may also explain the irritative reaction in skin tests with NMBAs.

Whether sugammadex blocks IgE binding to rocuronium is not known [19]. Jones and Turkstra [20] first raised the possibility of using sugammadex to treat rocuronium anaphylaxis in 2010. Since this first report, many other case reports have followed [21-28]. Whether this beneficial effect is due to the inhibition of IgE-mediated activation of mast cells remains elusive. It is possible that reversal of the neuromuscular blockade by sugammadex might help in restoring adequate cardiovascular function. It is also possible that standard treatment for anaphylaxis with adrenaline and fluids, etc. might additionally improve the condition of patients suffering from rocuronium anaphylaxis [24].

In order to elucidate this issue, a BAT was performed showing that sugammadex is able to prevent basophil activation by rocuronium, provided that sugammadex and rocuronium were preincubated prior to basophil stimulation. However, sugammadex was not able to stop an ongoing activation in this test [29]. These in vitro experiments were consistent with data from skin tests in rocuronium-sensitized patients. Clarke et al. [30] showed that these patients were anergic to sugammadex-bound rocuronium and concluded that sugammadex was able to prevent rocuronium from interacting with the immune system, presuming an underlying IgE-mediated mechanism. However, sugammadex was unable to attenuate the cutaneous hypersensitivity reaction after it had been triggered by rocuronium. Taken together, these data from BAT and skin tests suggest a similar mechanism being responsible for rocuronium-induced histamine release from basophils and mast cells mediated by MRGPRX2. Nevertheless, as it is not known whether the MRGPRX2 receptor is expressed on basophils, BAT does not allow differentiating true hypersensitivity from anaphylactoid reactions.

Our observations suggest that sugammadex might be beneficial to treat pseudoallergic reactions due to ro-

Int Arch Allergy Immunol 2016;169:256-262 

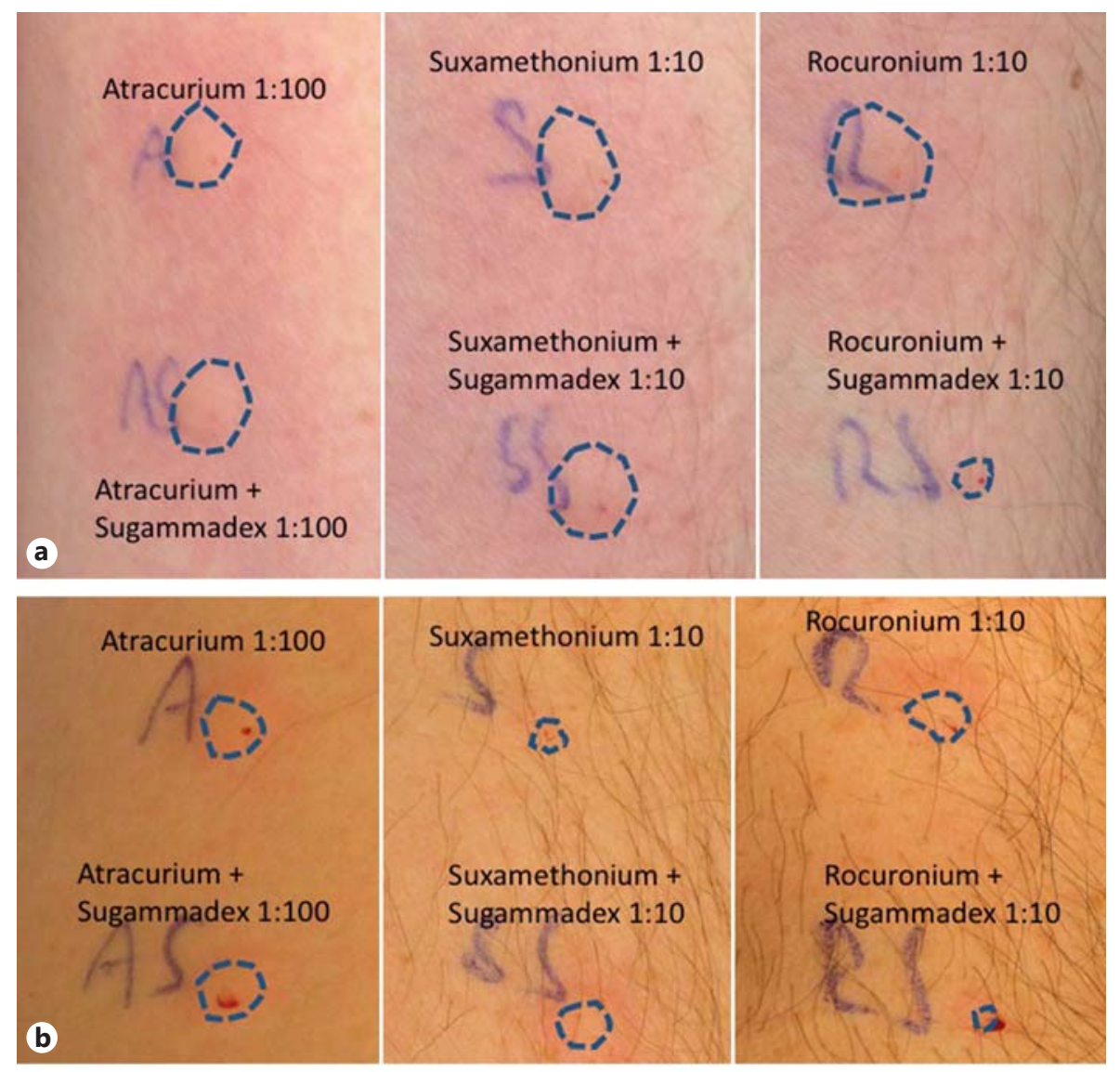

Fig. 2. a-c IDT with suxamethonium, atracurium and rocuronium alone and mixed with sugammadex (1:1 molecular for rocuronium, same volume for atracurium and suxamethonium) in 3 healthy individuals. When sugammadex was mixed before the IDT, the irritative (pseudoallergic) skin reaction of rocuronium was specifically attenuated, while atracurium and suxamethonium were not affected.
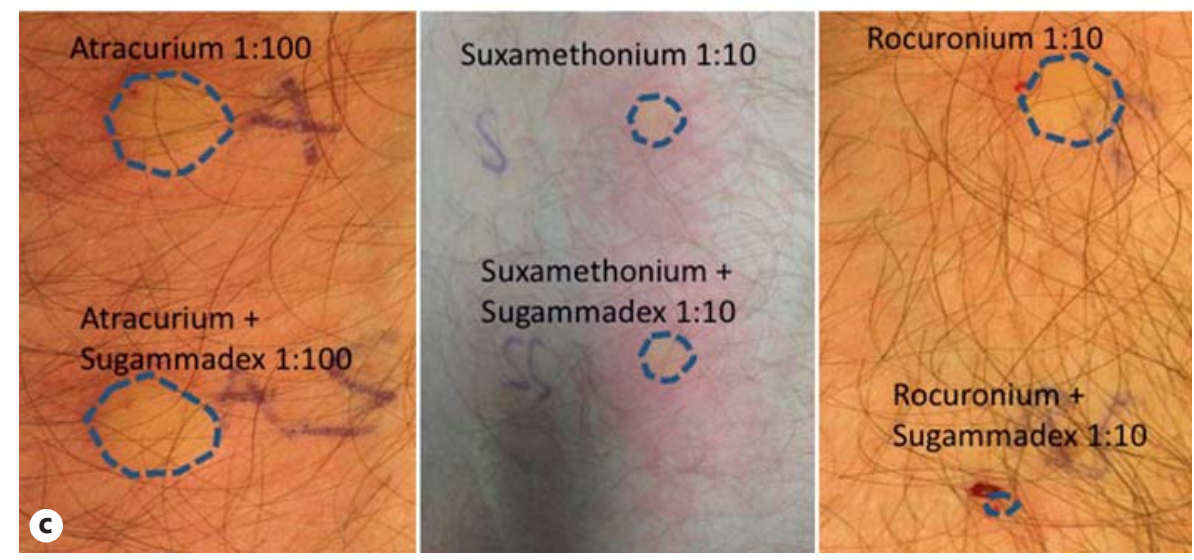

curonium, due to the likely inhibition of rocuroniummediated MRGPRX2 activation. The rapid clinical improvement seen during anesthesia in the 3 reported patients might be explained by the high affinity of sugammadex to rocuronium, possibly inducing cleavage of MRGPRX2 receptor-bound rocuronium.

Sugammadex has been designed to specifically encapsulate rocuronium [13]. It is not expected to influence the binding of other molecules to mast cells or IgE. Nevertheless, in order to test whether sugammadex might have an effect on pseudoallergic reactions to other compounds, we tested its effects on atracurium and suxamethonium, two NMBAs but with different chemical structures. We performed prick tests and IDTs in 3 healthy individuals who had never had one of these compounds injected. We mixed the same amount of sugammadex $\left(\right.$ Bridion $^{\circledR}$; MSD 
Fig. 3. a, b Prick tests with grass pollen and mold extracts in 2 atopic individuals. Adding sugammadex to the extracts before the prick test did not alter the reaction.
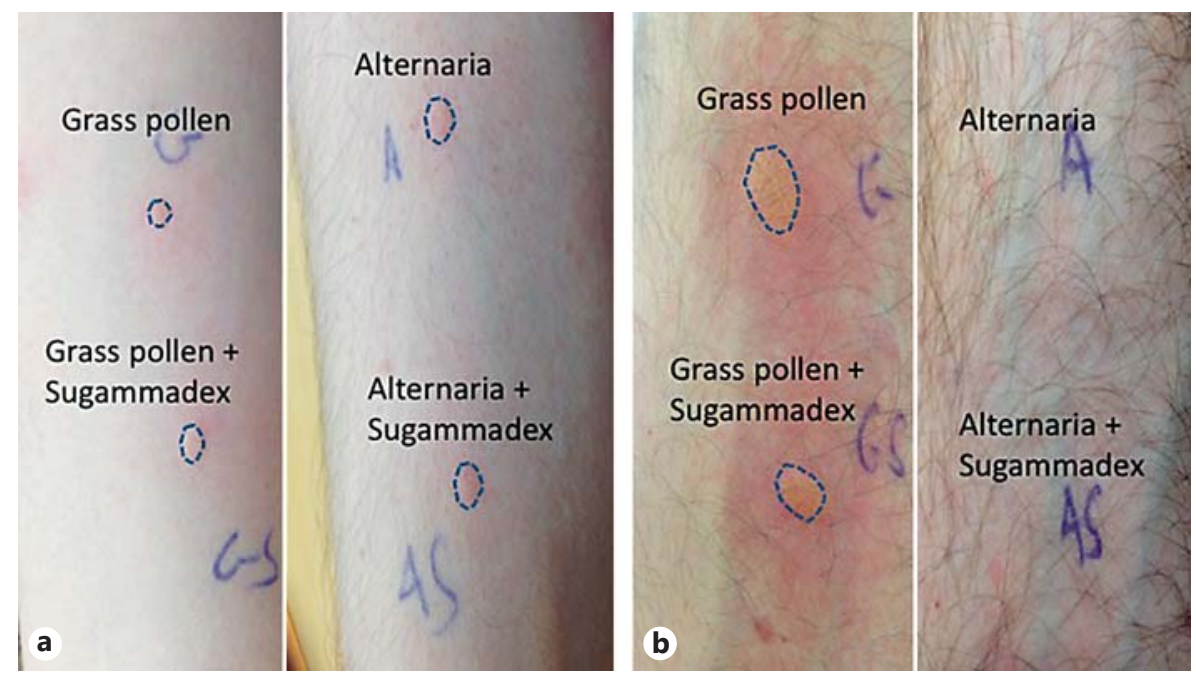

AG, Luzern, Switzerland) to atracurium (Atracurium Labatec $^{\circledR}$; Labatec-Pharma SA, Meyrin, Switzerland), suxamethonium (Lysthenon ${ }^{\circledR}$; Takeda Pharma AG, Pfäffikon, Switzerland) and rocuronium (Esmeron ${ }^{\circledR}$; MSD AG, Luzern, Switzerland), as tested previously in our 3 patients. The prick tests with pure rocuronium, suxamethonium and atracurium were negative and sugammadex had no effects when added to these drugs before testing. The IDTs with atracurium (dilution 1:100) and suxamethonium (dilution 1:10) were positive (both irritative). Adding sugammadex before testing did not affect the test result. On the contrary, the rocuronium IDT (dilution 1:10) was positive (irritative) when tested alone, and negative when tested after mixing sugammadex in a 1:1 molar dilution (fig. 2), except in 1 healthy individual, in whom the IDT with rocuronium mixed with sugammadex (dilution 1:10) was positive, but with a smaller papule and erythema than rocuronium (dilution 1:10) alone (fig. 2a). This confirmed the specificity of sugammadex for inhibiting rocuroniuminduced pseudoallergic reactions, and not other NMBAinduced pseudoallergic reactions. Moreover, in order to investigate the effects of sugammadex in classical IgE-me- diated hypersensitivity reactions, we performed prick tests in two atopic individuals, adding sugammadex to commercial grass pollen (Allergopharma, Reinbek, Germany) and Alternaria tenuis mold extracts (Alyostal ${ }^{\circledR}$; Stallergenes SA, Antony, France). Adding sugammadex did not alter the positive prick test reaction in the two atopic controls (fig. 3). These observations speak against an unspecific stabilizing effect of sugammadex on mast cells and support our hypothesis that sugammadex suppresses rocuronium-specific, non-IgE-mediated mast cell activation.

Sugammadex was recently also shown to be useful in the treatment of 2 cases of perioperative anaphylaxis due to antibiotic hypersensitivity in patients having received rocuronium. However, sugammadex was ineffective in anaphylaxis due to proven rocuronium hypersensitivity [14]. These observations do not argue against our hypothesis, and although we cannot exclude other mechanisms being involved in the rapid clinically favorable response seen in the reported patients, we suggest that sugammadex could be used to reverse pseudoallergic reactions to rocuronium, in addition to standard treatment including adrenaline.

\section{References}

Pseudoallergic Reaction to Rocuronium Reversed by Sugammadex
1 Dong SW, Mertes PM, Petitpain N, Hasdenteufel F, Malinovsky JM; GERAP: Hypersensitivity reactions during anesthesia: results from the ninth French survey (20052007). Minerva Anestesiol 2012;78:868878.

2 Florvaag E, Johansson SG, Oman H, Venemalm L, Degerbeck F, Dybendal T, Lundberg M: Prevalence of IgE antibodies to morphine: relation to the high and low incidences of
NMBA anaphylaxis in Norway and Sweden, respectively. Acta Anaesthesiol Scand 2005; 49:437-444.

3 Johansson SG, Florvaag E, Oman H, Poulsen LK, Mertes PM, Harper NJ, Garvey LH, Gerth van Wijk R, Metso T, Irgens A, Dybendal T, Halsey J, Seneviratne SL, Guttormsen AB: National pholcodine consumption and prevalence of IgE-sensitization: a multicentre study. Allergy 2010;65:498-502. 
4 Rouzaire P, Nosbaum A, Mullet C, Diot N, Dubost R, Bienvenu F, Guilloux L, Piriou V, Bienvenu J, Berard F: Immediate allergic hypersensitivity to quinolones associates with neuromuscular blocking agent sensitization. J Allergy Clin Immunol Pract 2013;1:273-279. e1.

5 Bom A, Bradley M, Cameron K, Clark JK, van Egmond J, Feilden H, MacLean EJ, Muir AW, Palin R, Rees DC, Zhang MQ: A novel concept of reversing neuromuscular block: chemical encapsulation of rocuronium bromide by a cyclodextrin-based synthetic host. Angew Chem Int Ed Engl 2002;41:266-270.

6 Harper NJ, Dixon T, Dugue P, Edgar DM, Fay A, Gooi HC, Herriot R, Hopkins P, Hunter JM, Mirakian R, Pumphrey RS, Seneviratne SL, Walls AF, Williams P, Wildsmith JA, Wood P, Nasser AS, Powell RK, Mirakhur R, Soar J; Working Party of the Association of Anaesthetists of Great Britain and Ireland: Suspected anaphylactic reactions associated with anaesthesia. Anaesthesia 2009;64:199211.

7 Mertes PM, Moneret-Vautrin DA, Leynadier F, Laxenaire MC: Skin reactions to intradermal neuromuscular blocking agent injections: a randomized multicenter trial in healthy volunteers. Anesthesiology 2007;107:245-252.

8 Dhonneur G, Combes X, Chassard D, Merle JC: Skin sensitivity to rocuronium and vecuronium: a randomized controlled pricktesting study in healthy volunteers. Anesth Analg 2004;98:986-989.

9 Brockow K, Garvey LH, Aberer W, Atanaskovic-Markovic M, Barbaud A, Bilo MB, et al: Skin test concentrations for systemically administered drugs - an ENDA/EAACI Drug Allergy Interest Group position paper. Allergy 2013;68:702-712.

10 Ebo DG, Venemalm L, Bridts CH, Degerbeck F, Hagberg H, De Clerck LS, Stevens WJ: Immunoglobulin $\mathrm{E}$ antibodies to rocuronium: a new diagnostic tool. Anesthesiology 2007; 107:253-259.

11 Schaller SJ, Fink H: Sugammadex as a reversal agent for neuromuscular block: an evidencebased review. Core Evid 2013;8:57-67.
12 Simons FE, Ardusso LR, Dimov V, Ebisawa M, El-Gamal YM, Lockey RF, Sanchez-Borges M, Senna GE, Sheikh A, Thong BY, Worm M, World Allergy Organization: World Allergy Organization Anaphylaxis Guidelines: 2013 update of the evidence base. Int Arch Allergy Immunol 2013;162:193-204.

13 Czarnetzki C, Tassonyi E, Lysakowski C, Elia N, Tramer MR: Efficacy of sugammadex for the reversal of moderate and deep rocuronium-induced neuromuscular block in patients pretreated with intravenous magnesium: a randomized controlled trial. Anesthesiology 2014;121:59-67.

14 Platt PR, Clarke RC, Johnson GH, Sadleir PH: Efficacy of sugammadex in rocuronium-induced or antibiotic-induced anaphylaxis: a case-control study. Anaesthesia 2015;70: 1264-1267.

15 Bjornsson HM, Graffeo CS: Improving diagnostic accuracy of anaphylaxis in the acute care setting. West J Emerg Med 2010;11:456461.

16 Dybendal T, Guttormsen AB, Elsayed S, Askeland B, Harboe T, Florvaag E: Screening for mast cell tryptase and serum IgE antibodies in 18 patients with anaphylactic shock during general anaesthesia. Acta Anaesthesiol Scand 2003;47:1211-1218.

17 Krishna MT, Huissoon A: Peri-operative anaphylaxis: beyond drugs and latex. Int Arch Allergy Immunol 2015;167:101-102.

18 McNeil BD, Pundir P, Meeker S, Han L, Undem BJ, Kulka M, Dong X: Identification of a mast-cell-specific receptor crucial for pseudo-allergic drug reactions. Nature 2015;519: 237-241.

19 Baldo BA, McDonnell NJ, Pham NH: Drugspecific cyclodextrins with emphasis on sugammadex, the neuromuscular blocker rocuronium and perioperative anaphylaxis: implications for drug allergy. Clin Exp Allergy 2011;41:1663-1678.

20 Jones PM, Turkstra TP: Mitigation of rocuronium-induced anaphylaxis by sugammadex: the great unknown. Anaesthesia 2010;65: 89-90.
21 Badaoui R, Popov I, Dupont H: A case of rocuronium-induced anaphylactic shock, improved by sugammadex (in French). Can J Anaesth 2012;59:909-910.

22 Funnell AE, Griffiths J, Hodzovic I: A further case of rocuronium-induced anaphylaxis treated with sugammadex. Br J Anaesth 2011; 107:275-276.

23 Kawano T, Tamura T, Hamaguchi M, Yatabe T, Yamashita K, Yokoyama M: Successful management of rocuronium-induced anaphylactic reactions with sugammadex: a case report. J Clin Anesth 2012;24:62-64.

24 McDonnell NJ, Pavy TJ, Green LK, Platt PR: Sugammadex in the management of rocuronium-induced anaphylaxis. Br J Anaesth 2011;106:199-201.

25 Raft J, Leclercq M, Longrois D, Meistelman C: Fast recovery of haemodynamic and ventilatory functions after sugammadex bolus following rocuronium-induced anaphylactic shock refractory to conventional treatment (in French). Ann Fr Anesth Reanim 2012;31: 158-161.

26 Motamed C, Baguenard P, Bourgain JL: Possible mitigation of rocuronium-induced anaphylaxis after administration of sugammadex. J Anaesthesiol Clin Pharmacol 2012;28: 127-128.

27 Barthel F, Stojeba N, Lyons G, Biermann C, Diemunsch P: Sugammadex in rocuronium anaphylaxis: dose matters. Br J Anaesth 2012; 109:646-647

28 Sirieix D, Latreille S, Raft J: Rapid hemodynamic recovery after early epinephrine and sugammadex co-administration during rocuronium-induced anaphylactic reaction (in French). Ann Fr Anesth Reanim 2014;33: 602-603.

29 Leysen J, Bridts CH, de Clerck LS, Ebo DG: Rocuronium-induced anaphylaxis is probably not mitigated by sugammadex: evidence from an in vitro experiment. Anaesthesia 2011;66:526-527.

30 Clarke RC, Sadleir PH, Platt PR: The role of sugammadex in the development and modification of an allergic response to rocuronium: evidence from a cutaneous model. Anaesthesia 2012;67:266-273. 